\title{
Geochemical signal of paleoenvironmental changes across Jurassic Cretaceous boundary (eastern Southern Alps)
}

B. RoŽIČ ${ }^{1}$, J. GRABOWSKY ${ }^{2}$, J. IWAŃSCUK ${ }^{2}$ AND P. ŽVAB

$$
\text { ROŽIČ }^{1}
$$

${ }^{1}$ Department of Geology, Faculty of Natural Sciences and Engineering, Univ. of Ljubljana, Aškerčeva 12, 1000 Ljubljana (*correspondence: bostjan.rozic@ntf.uni-lj.si) ${ }^{2}$ Polish Geological Institute - National Research Institute,

Rakowiecka 4, 00-975 Warszawa, Poland

Pelagic sediments contain richest geochemical record of paleoenvironmental changes. In last decades special focus was dedicated to different geological stratigraphic boundaries with aim to understand major evolutionary turnovers on these intervals. Among these, despite its importance, Jurassic Cretaceous boundary (JCB) remains poorly defined and it remains the last Phanerozoic system boundary without the GSSP. For this reason, detailed integrated studies of this boundary are valuable. In our study we deal with pelagic succession from the Slovenian Basin, Ladinian to endCretaceous deep-water unit of the eastern Southern Alps. Studied section starts with $5 \mathrm{~m}$ of the Lower Tithonian, clayrich radiolarian cherts that with sharp transition pass to $35 \mathrm{~m}$ thick formation of Upper Tithonian - Berriasian pelagic limestone that contains rare chert nodules and becomes more marly towards the top of the section. For geochemical measurements portable XRF was used and spectral gamma data supplemented with Magnetic susceptibility (MS) measurements. Lithogenic elements ( $\mathrm{Al}, \mathrm{Rb}, \mathrm{Ti}, \mathrm{Fe}$, etc.) and MS show prominent decrease towards upper Tithonian, reach minimum close to supposed JCB interval, and rise again towards the top of the section. We relate it to eustatic cycle and particularly to the aridification in the beginning of the Berriasian. The latter is indicated also by the highest $\mathrm{K} / \mathrm{Ti}$ ratios in the JCB interval. U/Th ratio indicate the most oxic conditions in the JCB interval. Ca rises greatly above the formation boundary (prior to JCB) and it is contrasted by the Si content. We relate it to evolutionary event that is related to increased fertility of surface waters that might reflect increased upwelling. This is additionally supported by constantly rising $\mathrm{Ba}$ values. Investigations were financially supported by the project 2016/21/B/ST10/02941 of the National Science Centre, Poland and Slovenian Research Agency - research core funding No. P1-0195(B). For further research we plan ICP-MS comperative method, $\mathrm{C}$ and $\mathrm{O}$ isotope analysis, calpionellid biostratigraphy, and magnetostratigraphy. 